\title{
Pyrogallol as a glutathione depletor induces apoptosis in HeLa cells
}

\author{
YONG HWAN HAN, SUNG ZOO KIM, SUHN HEE KIM and WOO HYUN PARK
}

\begin{abstract}
Department of Physiology, Medical School, Institute for Medical Sciences, Center for Healthcare Technology Development, Chonbuk National University, Jeonju 561-180, Korea
\end{abstract}

Received January 24, 2008; Accepted February 28, 2008

\begin{abstract}
Pyrogallol, a polyphenol, is known to be a superoxide anion $\left(\mathrm{O}_{2}^{-*}\right)$ generator. We investigated the involvement of glutathione $(\mathrm{GSH})$ and reactive oxygen species (ROS) in pyrogallol-induced HeLa cell death. We measured the changes of ROS levels, GSH levels, sub-G1 cells, annexin V/PI staining cells and mitochondria membrane potential $\left(\Delta \Psi_{\mathrm{m}}\right)$ in HeLa cells treated with pyrogallol and/or ROS scavenger. The intracellular ROS levels were decreased or increased depending on the concentration of pyrogallol. The level of $\mathrm{O}_{2}{ }^{--}$was significantly increased and superoxide dismutase (SOD) activity was down-regulated by pyrogallol. Pyrogallol reduced intracellular GSH content in HeLa cells. The ROS scavengers, Tempol, Tiron, Trimetazidine and $\mathrm{N}$-acetylcysteine (NAC), did not down-regulate the production of $\mathrm{O}_{2}{ }^{-}$. However, treatment with NAC showed the recovery of GSH depletion and significantly rescued cells from pyrogallolinduced apoptosis. In addition, the recovery of GSH depletion by SOD and catalase was accompanied by the decrease of apoptosis levels. Furthermore, NAC and SOD significantly inhibited CMF-negative (GSH-depleted) and PI-positive cells induced by pyrogallol. Taken together, pyrogallol potently increased intracellular $\mathrm{O}_{2}{ }^{--}$levels and decreased GSH content in HeLa cells, and NAC, SOD and catalase significantly
\end{abstract}

Correspondence to: Dr Woo Hyun Park or Suhn Hee Kim, Department of Physiology, Medical School, Chonbuk National University, Jeonju 561-180, Korea

E-mail: parkwh71@chonbuk.ac.kr

E-mail: shkim@chonbuk.ac.kr

Abbreviations: ROS, reactive oxygen species; NADPH, nicotine adenine diphosphate; XO, xanthine oxidase; SOD, superoxide dismutase; PARP, poly(ADP-ribose) polymerase; FBS, fetal bovine serum; PI, propidium iodide; NAC, N-acetylcysteine; PBS, phosphate buffer saline; FITC, fluorescein isothiocyanate; $\mathrm{H}_{2}$ DCFDA, 2',7'-dichlorodihydrofluorescein diacetate; DHE, dihydroethidium; GSH, N-(N-L- $\gamma$-glutamyl-L-cysteinyl)glycine; CMFDA, 5-chloromethylfluorescein diacetate

Key words: pyrogallol, reactive oxygen species, apoptosis, HeLa, reactive oxygen species scavenger, glutathione rescued HeLa cells from pyrogallol-induced apoptosis accompanied by the recovery of GSH depletion.

\section{Introduction}

Reactive oxygen species (ROS) include hydrogen peroxide $\left(\mathrm{H}_{2} \mathrm{O}_{2}\right)$, superoxide anion $\left(\mathrm{O}_{2}{ }^{\circ}\right)$ and hydroxyl radical $\left({ }^{\circ} \mathrm{OH}\right)$. They have recently been implicated in the regulation of many important cellular events, including transcription factor activation, gene expression, differentiation and proliferation (1-3). ROS are formed as by-products of mitochondrial respiration or oxidases including nicotine adenine diphosphate (NADPH) oxidase, xanthine oxidase (XO) and certain arachidonic acid oxygenases (4). A change in the redox state of the tissue implies a change in ROS generation or metabolism. Principal metabolic pathways include superoxide dismutase (SOD), which is expressed as extracellular, intracellular, and mitochondrial isoforms. They metabolize $\mathrm{O}_{2}{ }^{-}$to $\mathrm{H}_{2} \mathrm{O}_{2}$. Further metabolism by peroxidases that include catalase and glutathione peroxidase yields $\mathrm{O}_{2}$ and $\mathrm{H}_{2} \mathrm{O}$ (5). Cells possess antioxidant systems to control the redox state, which is important for their survival. Excessive production of ROS gives rise to the activation of events which lead to death and survival in many different types of cells (6-9). The accurate mechanisms involved in cell death induced by ROS are not fully understood and the protective effect mediated by some antioxidants remains controversial.

Pyrogallol is a polyphenol and is known to be an $\mathrm{O}_{2}{ }^{-}$ generator $(10,11)$. This compound is often used to investigate the role of $\mathrm{O}_{2}^{--}$in biological systems. For example, pyrogallol was shown to induce the $\mathrm{O}_{2}{ }^{-}$-mediated death of several types of cell such as mouse myocytes (12), and mesangial (13), human lymphoma (10), and human glioma cells (14). Recently, we showed that pyrogallol inhibited the growth of HeLa cells with an $\mathrm{IC}_{50}$ of about $45 \mu \mathrm{M}$ (15). Pyrogallol efficiently induced apoptosis, as evidenced by the flow cytometric detection of sub-G1 DNA content, annexin V binding assay and DAPI staining. This apoptotic process was accompanied by the loss of mitochondrial membrane potential $\left(\Delta \Psi_{\mathrm{m}}\right), \mathrm{Bcl}-2$ down-regulation, the activation of caspase-3 and PARP degradation (15).

In the present study, we evaluated an involvement of GSH and ROS such as $\mathrm{H}_{2} \mathrm{O}_{2}$ and $\mathrm{O}_{2}{ }^{--}$in pyrogallol-induced HeLa cell death and investigated whether ROS scavengers rescue cells from pyrogallol-induced HeLa cell death. 


\section{Materials and methods}

Cell culture. Human cervical adenocarcinoma HeLa cells were maintained in humidified incubator containing $5 \% \mathrm{CO}_{2}$ at $37^{\circ} \mathrm{C}$. HeLa cells were cultured in Dulbecco's modified Eagle's medium (DMEM) supplemented with $10 \%$ fetal bovine serum (FBS) and 1\% penicillin-streptomycin (Gibco BRL, Grand Island, NY). Cells were routinely grown in 100-mm plastic tissue culture dishes (Nunc, Roskilde, Denmark) and harvested with a solution of trypsin-EDTA when they were in logarithmic phase of growth. Cells were maintained in these culture conditions for all experiments.

Reagents. Pyrogallol purchased from Sigma-Aldrich Chemical Company (St. Louis, MO) was dissolved in $\mathrm{H}_{2} \mathrm{O}$ at $1 \times 10^{-1} \mathrm{M}$ as a stock solution. The cell permeable $\mathrm{O}_{2}{ }^{-}$scavengers, 4-hydroxy-TEMPO (4-hydroxyl-2,2,6,6-tetramethylpierydine-1oxyl) (Tempol) and Tiron (4,5-dihydroxyl-1,3-benzededisulfonic acid), Trimetazidine [1-(2,3,4-trimethoxibenzyl)piperazine] and NAC (N-acetylcysteine) were obtained from Sigma and dissolved in designated solution buffer at $1 \times 10^{-1} \mathrm{M}$ as a stock solution. SOD and catalase were obtained from Sigma and dissolved in $50 \mathrm{mM}$ potassium phosphate buffer at $4733 \mathrm{U} / \mathrm{ml}$. All stock solutions were wrapped in foil and kept at 4 or $-20^{\circ} \mathrm{C}$.

Sub-G1 analysis. Sub-G1 distributions were determined by staining DNA with propidium iodide (PI) (Sigma) as described previously $(16,17)$. PI is a fluorescent biomolecule that can be used to stain DNA. Briefly, $1 \times 10^{6}$ cells were incubated with the designated drug doses for $72 \mathrm{~h}$. The cells were then washed in phosphate-buffered saline (PBS) and fixed in $70 \%$ ethanol. The cells were again washed with PBS and then incubated with PI $(10 \mu \mathrm{g} / \mathrm{ml})$ with simultaneous treatment of RNase at $37^{\circ} \mathrm{C}$ for $30 \mathrm{~min}$. The percentages of cells containing the sub-G1 DNA were measured with a FACStar flow cytometer (Becton Dickinson, San Jose, CA) and analyzed using Lysis II and CellFit software (Becton Dickinson).

Annexin V/PI staining. Apoptosis was determined by staining cells with annexin V-fluorescein isothiocyanate (FITC) (Ex/Em 488/519 nm) and PI (Ex/Em 488/617 nm) labeling, as annexin $\mathrm{V}$ can identify the externalization of phosphatidylserine during the progression of apoptosis, and therefore detect cells early in apoptosis. PI can also be used to differentiate necrotic, apoptotic and normal cells. This agent is membrane-impermeant and is generally excluded from viable cells. Briefly, $1 \times 10^{6}$ cells were incubated with the designated drug doses for $72 \mathrm{~h}$. Cells were washed twice with cold PBS and then re-suspended in $500 \mu 1$ of binding buffer [10 mM HEPES/NaOH (pH 7.4), $140 \mathrm{mM} \mathrm{NaCl}, 2.5 \mathrm{mM} \mathrm{CaCl}_{2}$ ] at a concentration of $1 \times 10^{6}$ cells $/ \mathrm{ml}$. Annexin V-FITC (5 $\left.\mu \mathrm{l}\right)$ (PharMingen, San Diego, CA) and PI $(1 \mu \mathrm{g} / \mathrm{ml})$ were then added to these cells, which were analyzed with a FACStar flow cytometer. Viable cells were negative for both PI and annexin V; apoptotic cells were positive for annexin $\mathrm{V}$ and negative for PI, whereas late apoptotic dead cells displayed both high annexin V and PI labeling. Non-viable cells, which underwent necrosis, were positive for PI and negative for annexin $\mathrm{V}$.
Measurement of mitochondrial membrane potential $\left(\Delta \Psi_{m}\right)$. The mitochondrial membrane was monitored using the fluorescent dye Rhodamine 123, a cell-permeable cationic dye, which preferentially enters mitochondria due to a highly negative mitochondrial membrane potential $\left(\Delta \Psi_{\mathrm{m}}\right)$. Depolarization of mitochondrial membrane potential $\left(\Delta \Psi_{\mathrm{m}}\right)$ results in the loss of Rhodamine 123 from the mitochondria and a decrease in intracellular fluorescence (Ex/Em 485/535 nm). Briefly, $1 \times 10^{6}$ cells were incubated with the designated doses of drugs for $72 \mathrm{~h}$. The cells were washed twice with PBS and incubated with Rhodamine $123(0.1 \mu \mathrm{g} / \mathrm{ml}$; Sigma $)$ at $37^{\circ} \mathrm{C}$ for $30 \mathrm{~min}$. PI $(1 \mu \mathrm{g} / \mathrm{ml})$ was subsequently added, and Rhodamine 123 and PI staining intensity were determined by flow cytometry.

Detection of intracellular $\mathrm{ROS}$ and $\mathrm{O}_{2}^{--}$concentration. The concentrations of intracellular general ROS such as $\mathrm{H}_{2} \mathrm{O}_{2}$, $\cdot \mathrm{OH}$ and $\mathrm{ONOO}^{-}$, were detected by means of an oxidationsensitive fluorescent probe dye, 2',7'-dichlorodihydro-fluorescein diacetate $\left(\mathrm{H}_{2} \mathrm{DCFDA}\right)$ (Invitrogen Molecular Probes, Eugene, OR). $\mathrm{H}_{2}$ DCFDA was deacetylated intracellularly by nonspecific esterase, which was further oxidized by cellular peroxides yielding the fluorescent compound 2,7-dichlorofluorescein (DCF) (Ex/Em 485/535 nm). Dihydroethidium (DHE) (Invitrogen Molecular Probes) is a fluorogenic probe that is highly selective for the detection of superoxide anion radicals $\left(\mathrm{O}_{2}{ }^{-}\right)$among ROS. DHE is cell permeable and reacts with superoxide anion to form ethidium, which in turn intercalates in the deoxyribonucleic acid, thereby exhibiting a red fluorescence (Ex/Em 515/595 nm). Briefly, cells were incubated with the designated doses of pyrogallol combined with or without ROS scavengers for $72 \mathrm{~h}$. Cells were then washed in PBS and incubated with $20 \mu \mathrm{M} \mathrm{H}_{2}$ DCFDA or $5 \mu \mathrm{M}$ DHE at $37^{\circ} \mathrm{C}$ for $30 \mathrm{~min}$ according to the manufacturer's instructions. DCF fluorescence and red fluorescence were detected by a FACStar flow cytometer. In particular, DCF fluorescence intensity was significantly increased in $\mathrm{H}_{2} \mathrm{O}_{2}$-treated $\mathrm{HeLa}$ cells (data not shown). For each sample, 5,000 or 10,000 events were collected. ROS levels were expressed as mean fluorescence intensity (MFI), which was calculated by CellQuest software.

Detection of intracellular glutathione (GSH). Cellular GSH levels were analyzed using 5-chloromethylfluorescein diacetate (CMFDA, Molecular Probes). CMFDA is a useful membrane-permeable dye (Ex/Em 492/517 nm) for determining levels of intracellular glutathione as previously described (18). Briefly, cells were incubated with the designated doses of pyrogallol with or without ROS scavengers for $72 \mathrm{~h}$. Cells were then washed in PBS and incubated with $5 \mu \mathrm{M}$ CMFDA at $37^{\circ} \mathrm{C}$ for $30 \mathrm{~min}$ according to the manufacturer's instructions. Cytoplasmic esterases convert nonfluorescent CMFDA to fluorescent 5-chloromethylfluorescein, which can then react with the glutathione (Ex/Em 522/595 nm). PI (1 $\mu \mathrm{g} / \mathrm{ml})$ was subsequently added, and CMF fluorescence and PI staining intensity were determined by a FACStar flow cytometer and calculated by CellQuest software. For each sample, 5,000 or 10,000 events were collected. 
$\mathbf{A}$
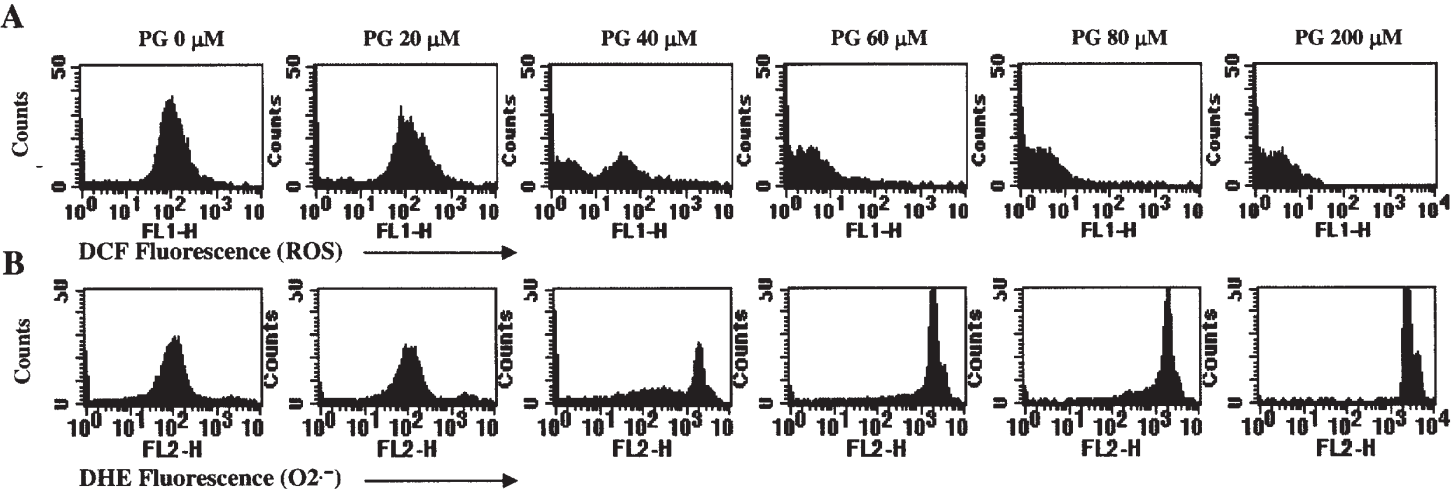

C

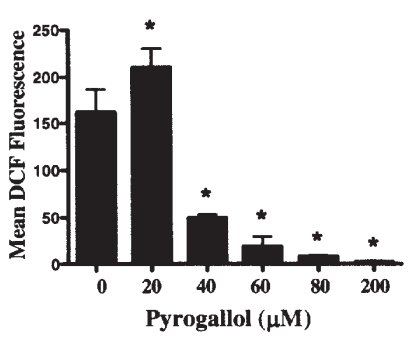

D

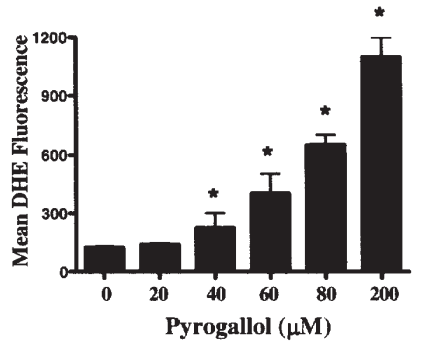

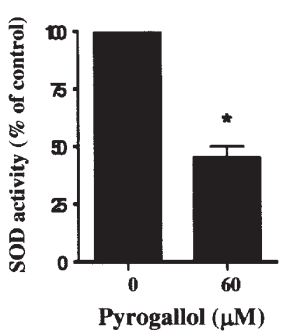

Figure 1. Effects of pyrogallol on ROS levels and SOD activity in HeLa cells. Exponentially growing cells were treated with the indicated amounts of pyrogallol for $72 \mathrm{~h}$. Intracellular general ROS (A) and intracellular $\mathrm{O}_{2}^{-}$(B) levels were determined by a FACStar flow cytometer as described in Materials and methods. (C) Means of DCF fluorescence levels shown in A. (D) Means of DHE fluorescence levels shown in B. (E) Change of SOD activity by pyrogallol (PG). ${ }^{*} \mathrm{p}<0.05$ compared with the pyrogallol-untreated control group.

A
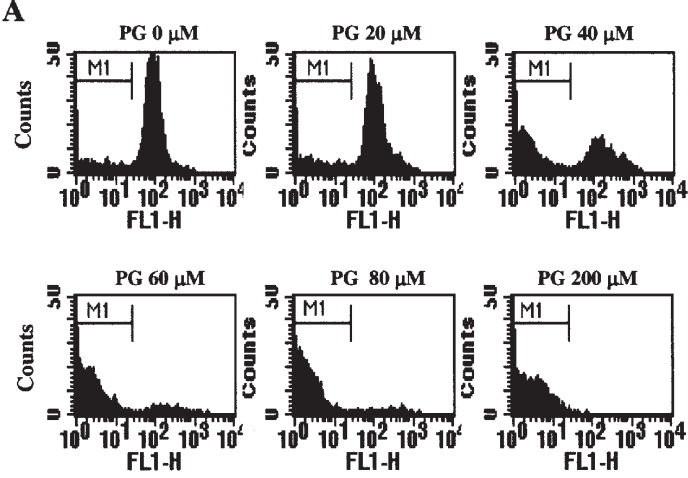

B

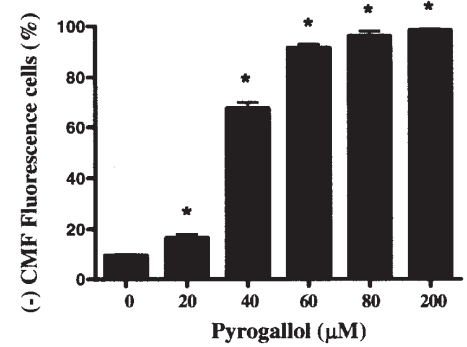

C
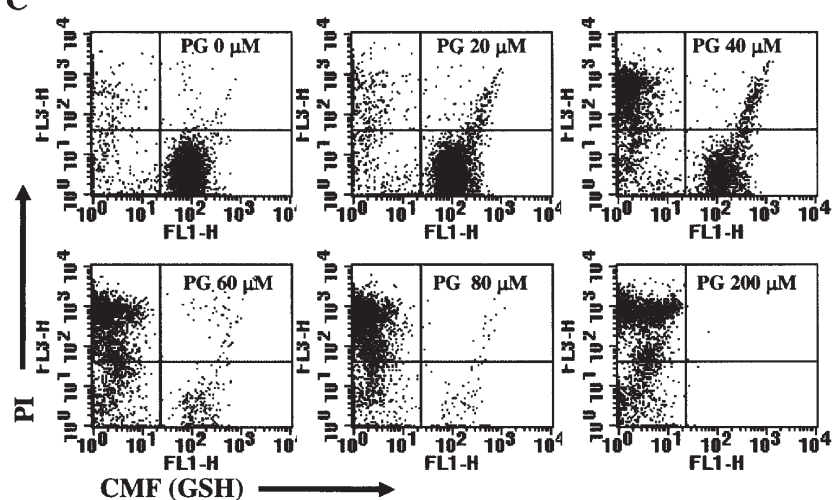

D

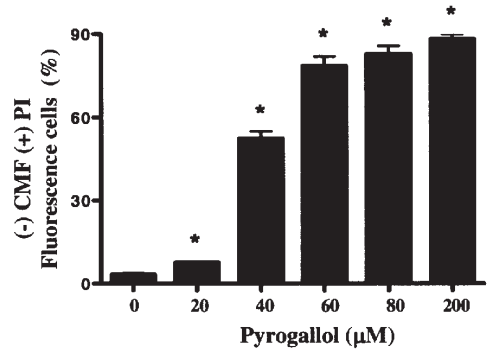

Figure 2. Effects of pyrogallol on GSH content and viability of HeLa cells. Exponentially growing cells were treated with the indicated amounts of pyrogallol for $72 \mathrm{~h}$. Intracellular GSH levels (A) were determined by a FACStar flow cytometer as described in Materials and methods. (B) Percent of CMF-negativefluorescent (M1-region; GSH-depleted) cells in pyrogallol-treated HeLa cells. (C) CMF-fluorescent cells and PI-positive staining cells (indicative of nonviable cells) were measured with a FACStar flow cytometer. (D) Percent of CMF-negative and PI-positive staining cells shown in C. "p $<0.05$ compared with the pyrogallol-untreated control group.

Measurement of cellular superoxide dismutase activity. The level of cellular SOD enzyme activity was measured using the SOD Assay Kit-WST (Fluka Co, Milwaukee, WI), which allows convenient SOD assaying by utilizing a highly water- soluble tetrazolium salt, WST-1 [2-(4-lodophenyl)-3-(4nitrophenyl)-5-(2,4-disulfophenyl)-2H-tetrazolium, monosodium salt] that produces a water-soluble formazan dye upon reduction with a superoxide anion. Briefly, the cells 
A
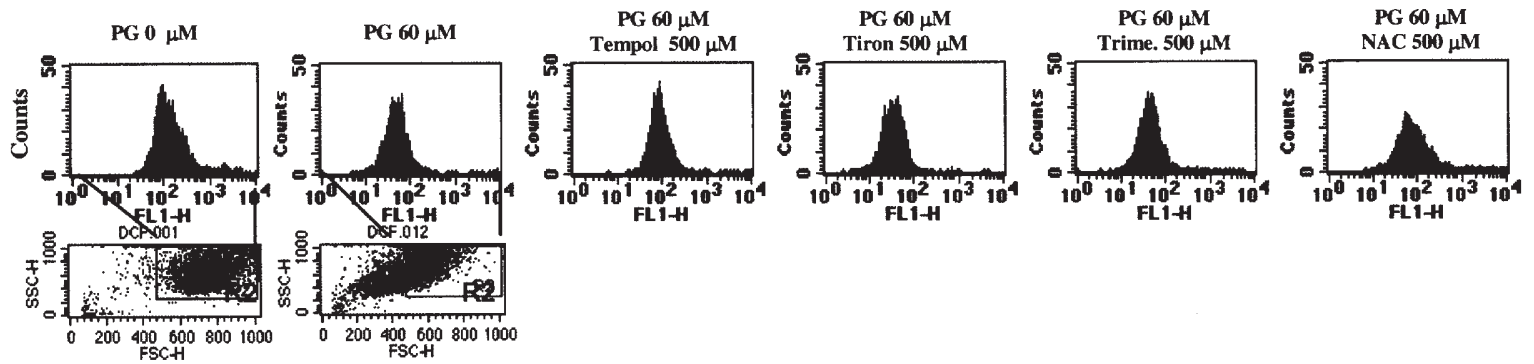

B
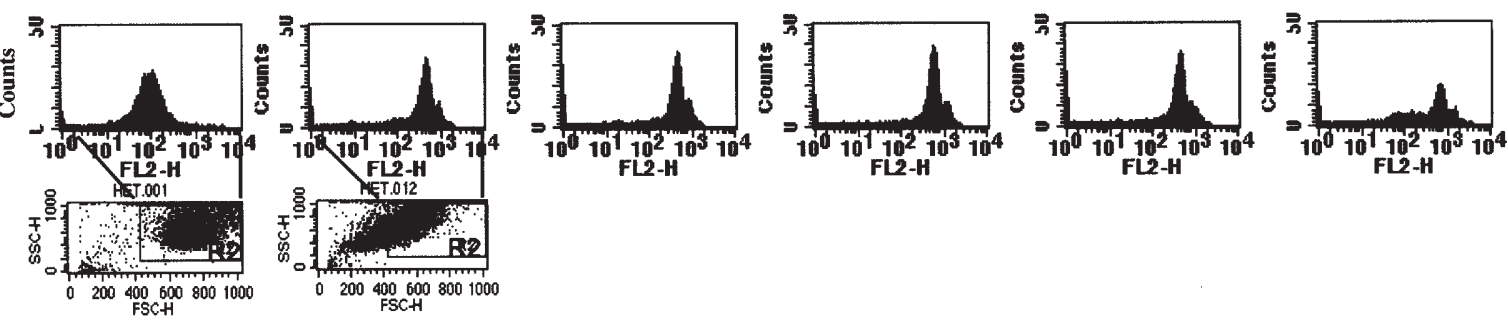

$\mathbf{C}$
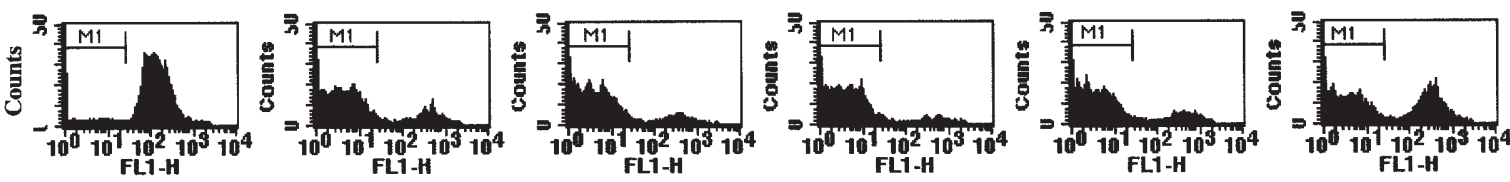

D

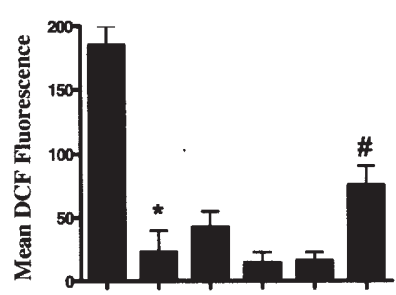

PG $60 \mu \mathrm{M}$ :

Tempol 500

Tiron $500 \mu \mathrm{M}$ :

Trime. $500 \mu \mathrm{M}$ :

NAC $500 \mu M$ :
$\mathbf{E}$

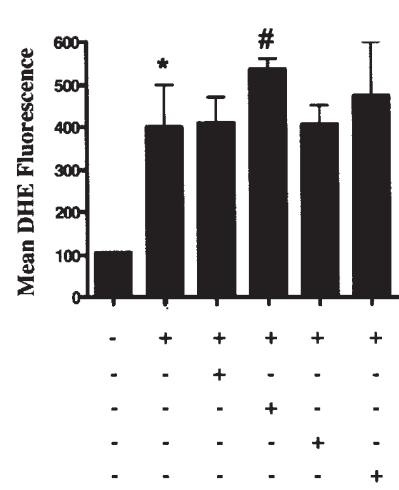

F

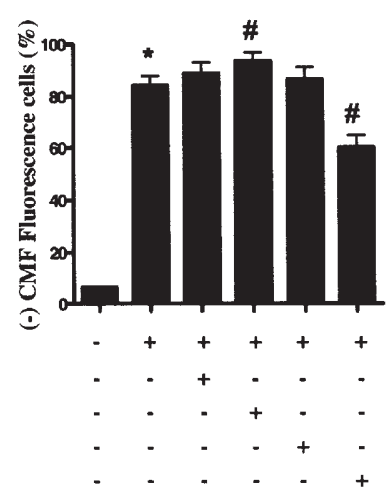

Figure 3. Effects of ROS scavengers on intracellular ROS and GSH content in pyrogallol-treated HeLa cells. Exponentially growing cells were treated with the indicated amounts of ROS scavengers in addition to pyrogallol (PG) for $72 \mathrm{~h}$. (A) Intracellular general ROS levels, derived from the cells in the R2 region of the FSC and SSC dot plot. (B) Intracellular $\mathrm{O}_{2}{ }^{--}$levels from the R2 region. (C) Intracellular GSH levels. (D) Means of DCF fluorescence levels shown in A. (E) Means of DHE fluorescence levels shown in B. (F) Percent of CMF-negative-fluorescent cells shown in C. *p<0.05 compared with the control group; ${ }^{\#} \mathrm{p}<0.05$ compared with the cells treated only with PG.

were incubated with the designated doses of pyrogallol for $72 \mathrm{~h}$, washed with PBS and suspended in five volumes of lysis buffer [20 mM HEPES (pH 7.9), 20\% Glycerol, $200 \mathrm{mM}$ $\mathrm{KCl}, 0.5 \mathrm{mM}$ EDTA, $0.5 \%$ NP40, $0.5 \mathrm{mM}$ DTT, $1 \%$ protease inhibitor cocktail (Sigma)]. The lysates were then collected and stored at $-20^{\circ} \mathrm{C}$ until further use. Supernatant protein concentration was determined by the Bradford method. Supernatant samples containing $30 \mu \mathrm{g}$ of total protein were used for the determination of SOD enzyme activity according to the manufacturer's instructions. After $10 \mathrm{~min}$ incubation, the WST-1 formazan was measured at $450 \mathrm{nM}$ using a microplate reader (Spectra Max 340, Molecular Devices Co., Sunnyvale, CA). The value for the experimental group was converted to the percentage of control group.

Statistical analysis. Results represent the mean of at least 2 or 3 independent experiments; the bars in the figures indicate standard deviation. Microsoft Excel or Instat software (GraphPad Prism4, San Diego, CA) was used to analyze the data. Student's t-test or one-way analysis of variance
(ANOVA) with post hoc analysis using Tukey's multiple comparison test were used for parametric data. Statistical significance was defined as $\mathrm{p}<0.05$.

\section{Results}

Effect of pyrogallol on ROS, SOD activity and GSH production in HeLa cells. We investigated the levels of ROS in pyrogallol-treated HeLa cells. To assess the production of intracellular ROS in pyrogallol-treated HeLa cells, we used $\mathrm{H}_{2}$ DCFDA fluorescence dye. We first screened HeLa cells with a broad range concentrations of pyrogallol and various incubation periods and chose the optimal range of pyrogallol doses (20-200 $\mu \mathrm{M})$ and incubation periods (short, 30-180 min, and long, $72 \mathrm{~h}$ ). As shown in Fig. 1A and C, intracellular ROS levels were markedly decreased in HeLa cells treated with 40-200 $\mu \mathrm{M}$ pyrogallol for $72 \mathrm{~h}$. In contrast, cells treated with $20 \mu \mathrm{M}$ pyrogallol showed an increase in ROS levels compared with pyrogallol-untreated control cells. Pyrogallol is a polyphenol compound and has been known to be an $\mathrm{O}_{2}{ }^{-}$ 
A

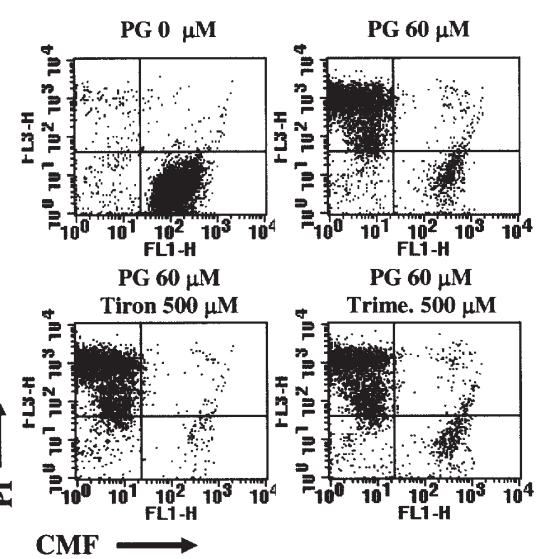

PG $60 \mu \mathrm{M}$

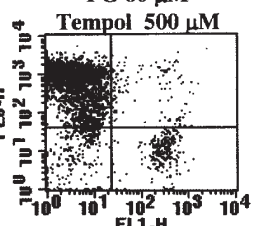

PG $60 \mu \mathrm{M}$

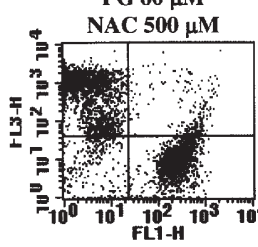

B

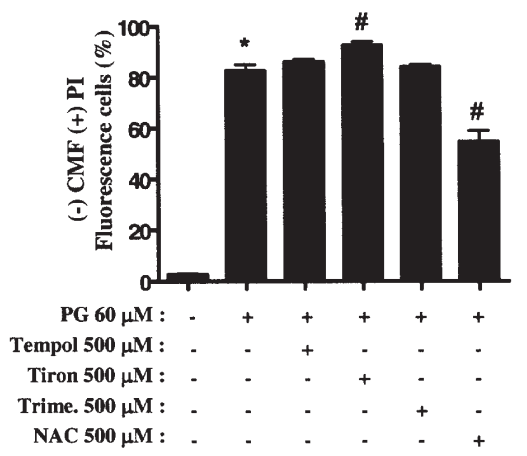

Figure 4. Effects of ROS scavengers on CMF and PI fluorescence in pyrogallol-treated HeLa cells. Exponentially growing cells were treated with the indicated amounts of ROS scavengers in addition to pyrogallol (PG) for $72 \mathrm{~h}$. (A) CMF-fluorescent cells and PI-positive staining cells were measured with a FACStar flow cytometer. (B) Percentages of CMF-negative and PI-positive staining cells shown in A. ${ }^{*} \mathrm{p}<0.05$ compared with the control group; ${ }^{\#} \mathrm{p}<0.05$ compared with the cells treated only with PG.

generator $(10,11)$. Therefore, we investigated the change of intracellular $\mathrm{O}_{2}^{--}$levels in pyrogallol-treated HeLa cells. Red fluorescence derived from DHE, indicating the accumulation of intracellular $\mathrm{O}_{2}{ }^{--}$, in pyrogallol-treated HeLa cells, was increased in a dose-dependent manner (Fig. 1B and D). We recently demonstrated that $60 \mu \mathrm{M}$ pyrogallol inhibited the growth of HeLa cells $~ 85 \%$ using MTT assay and induced apoptosis in $\sim 30 \%$ (15). In this experiment, we used a concentration of $60 \mu \mathrm{M}$ pyrogallol. This concentration was considered to be a suitable dose to differentiate apoptosis levels in the presence of pyrogallol versus apoptosis in the presence of pyrogallol and ROS scavengers including SOD and catalase. When treated with $60 \mu \mathrm{M}$ pyrogallol for the short time periods (30-180 min), HeLa cells showed a decrease in general ROS levels and an increase in $\mathrm{O}_{2}{ }^{-}$levels (data not shown). In addition, SOD activity was significantly decreased in $60 \mu \mathrm{M}$ pyrogallol-treated HeLa cells (Fig. 1E).

Cellular GSH has been shown to be crucial for the regulation of cell proliferation, cell cycle progression and apoptosis $(19,20)$. We therefore analyzed the GSH levels of HeLa cells by using CMF fluorescence. The M1 population of HeLa cells showed lower levels of intracellular GSH content (Fig. 2A). Pyrogallol significantly elevated the percentages of cells residing in the M1 population in a dosedependent manner at $72 \mathrm{~h}$ (Fig. 2A and B), which indicated the depletion of the intracellular GSH content in HeLa cells

following treatment with pyrogallol. Next, to evaluate whether the M1 population of cells in the negative CMFfluorescent region were dead, we performed additional staining of cells with PI in order to verify the disruption of the plasma membrane. As shown in Fig. $2 \mathrm{C}$ and D, many CMF-negative-fluorescent cells showed PI-positive staining, which indicated that cells showing lower levels of GSH content were dead. The proportion of CMF-depleted dead cells increased in the presence of pyrogallol in a dosedependent manner. In addition, when treated with $60 \mu \mathrm{M}$ pyrogallol for the short time periods (30-180 min), HeLa cells showed a decrease in GSH levels at these times (data not shown).

Effects of ROS scavengers on ROS production, GSH depletion and apoptosis in pyrogallol-treated HeLa cells. To determine whether ROS production and GSH depletion in pyrogalloltreated HeLa cells were changed by ROS scavengers, cellpermeable ROS scavengers, Tempol and Tiron (11), and a well-known antioxidant, NAC, were co-incubated with pyrogallol-treated HeLa cells for $72 \mathrm{~h}$. An anti-ischemic and metabolic agent, Trimetazidine was also used as an indirect antioxidant $(21,22)$. To measure the accurate intracellular fluorescence level of ROS, we used only the cells residing in the $\mathrm{R} 2$ region. These cells are considered to have intact plasma membrane (Fig. 3A and B). The scavengers, with the exception of NAC, did not significantly change the intracellular ROS levels in $60 \mu \mathrm{M}$ pyrogallol-treated cells (Fig. 3A and D). NAC increased the level of ROS in pyrogallol-treated cells. None of the scavengers reduced the $\mathrm{O}_{2}{ }^{-}$levels in pyrogalloltreated cells (Fig. 3B and E). In contrast, the treatment with Tiron increased the intracellular $\mathrm{O}_{2}^{--}$levels. The scavengers, excepting NAC, did not also inhibit depletion of the GSH content in pyrogallol-treated HeLa cells (Fig. 3C and F). Tiron showed instead the significant enhancement of GSH depletion (Fig. 3C and F). Treatment with NAC inhibited the GSH depletion in pyrogallol-treated cells at $72 \mathrm{~h}$ (Fig. 3C and F) and also recovered the reduced GSH levels in these cells at the early time points (30-180 min) (data not shown). Next, we evaluated whether the M1 population of cells in the negative CMF-fluorescent region were alive or dead. As shown in Fig. 4, the negative CMF fluorescent cells showed, on the whole, PI-positive staining, indicating that the cells showing GSH depletion were generally dead. The proportions of CMF-negative and PI-positive cells were significantly increased in Tiron-treated cells, indicating that Tiron exaggerated the disruption of the plasma membrane. Conversely, treatments with NAC reduced the proportions of CMFnegative and PI-positive cells. All of the ROS scavengers used in this experiment did not significantly alter the intracellular ROS and GSH levels in HeLa control cells (data not shown).

Next, we attempted to examine whether these scavengers inhibited pyrogallol-induced HeLa cell death. The scavengers, excepting NAC, did not prevent pyrogallol-induced apoptosis in the cells (Fig. 5). NAC significantly inhibited apoptosis compared with pyrogallol-treated cells (approximately 50 vs. $83 \%$ ) in view of sub-G1 cells, annexin V staining cells and the loss of mitochondrial membrane potential $\left(\Delta \Psi_{\mathrm{m}}\right)$. In contrast, Tiron intensified apoptosis levels in pyrogallol- 

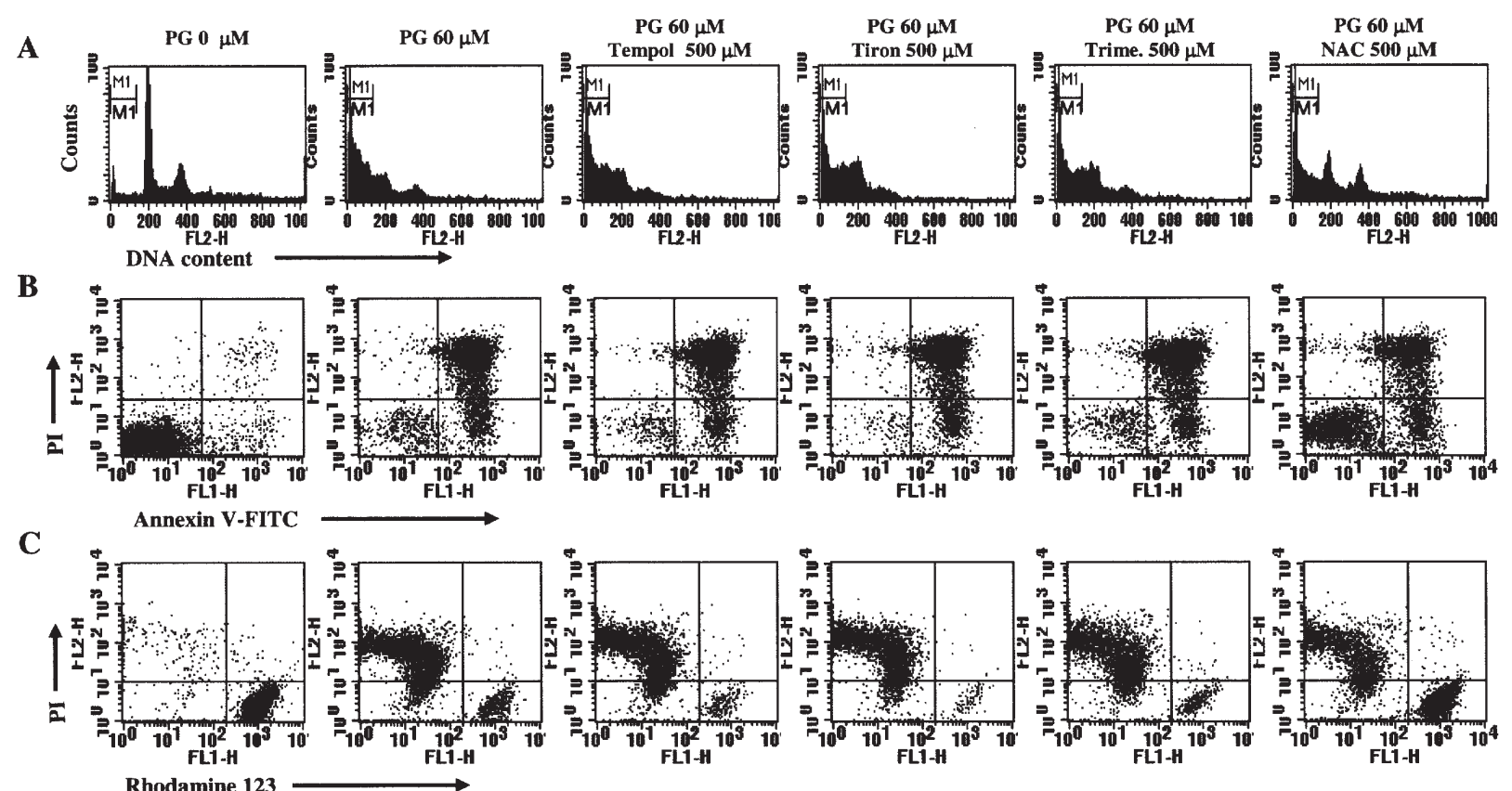

D

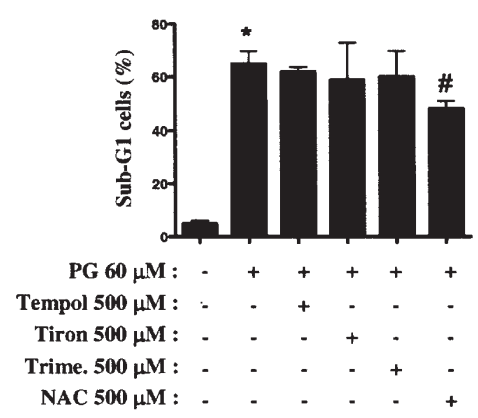

$\mathbf{E}$

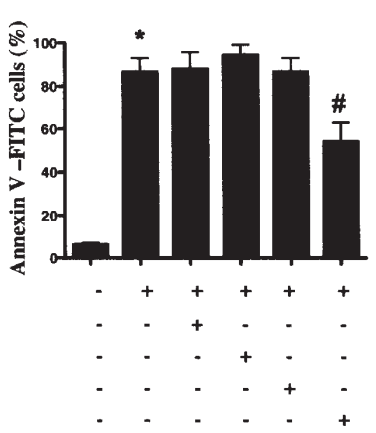

$\mathbf{F}$

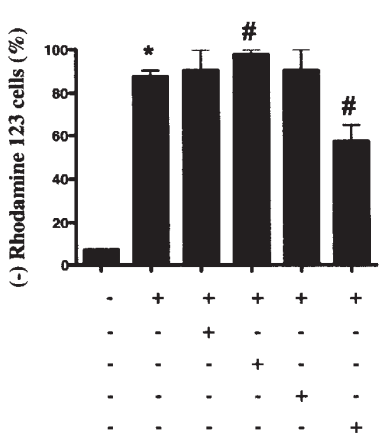

Figure 5. Effects of ROS scavengers on pyrogallol-induced apoptosis. Exponentially growing cells were treated with the indicated amounts of ROS scavengers in addition to pyrogallol (PG) for $72 \mathrm{~h}$. Sub-G1 cells (A), annexin V staining cells (B) and Rhodamine 123-negative staining cells (C) were measured with a FACStar flow cytometer. (D, E and F) Percentages of: sub-G1 population shown in A (D); annexin V-positive staining cells shown in B (E) and Rhodamine 123-negative staining cells shown in $\mathrm{C}(\mathrm{F}) .{ }^{*} \mathrm{p}<0.05$ compared with the control group; ${ }^{*} \mathrm{p}<0.05$ compared with the cells treated only with PG.
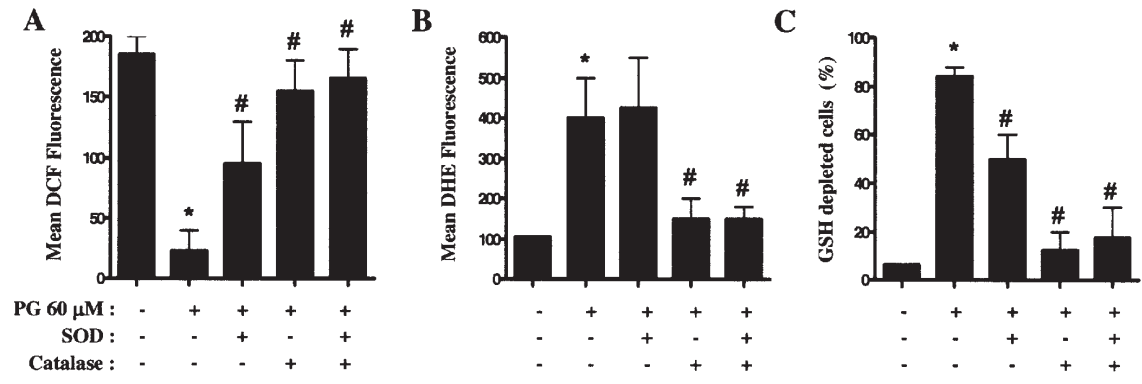

Figure 6. Effects of SOD and catalase on intracellular ROS and GSH production in pyrogallol-treated HeLa cells. Exponentially growing cells were treated with the indicated amounts of SOD, catalase and pyrogallol (PG) for $72 \mathrm{~h}$. The graphs show the means of (A) DCF-fluorescent cell levels (indicative of general ROS levels), (B) DHE-fluorescent cell levels (indicative of $\mathrm{O}_{2}{ }^{-*}$ levels) and (C) the percent of GSH-depleted cells. " $\mathrm{p}<0.05$ compared with the control group; ${ }^{*} \mathrm{p}<0.05$ compared with the cells treated only with PG.

treated HeLa cells as evidenced by annexin $\mathrm{V}$ staining cells and the loss of mitochondrial membrane potential $\left(\Delta \Psi_{\mathrm{m}}\right)$ (Fig. 5E and F). Additionally, the high concentrations (1 or $2.5 \mathrm{mM}$ ) of ROS scavengers, with the exception of NAC, were not used due to their toxicity in HeLa control cells, but the higher doses of NAC also strongly inhibited the death of HeLa cells induced by pyrogallol (data not shown).
Effects of SOD and catalase on ROS production, GSH depletion and apoptosis in pyrogallol-treated HeLa cells. Next, to determine whether ROS production and GSH depletion in pyrogallol-treated HeLa cells were changed by exogenous SOD and catalase, HeLa cells were treated with pyrogallol in the presence or absence of SOD $(30 \mathrm{U} / \mathrm{ml})$ or/and catalase $(30 \mathrm{U} / \mathrm{ml})$ for $72 \mathrm{~h}$. As shown in Fig. 6A, SOD 

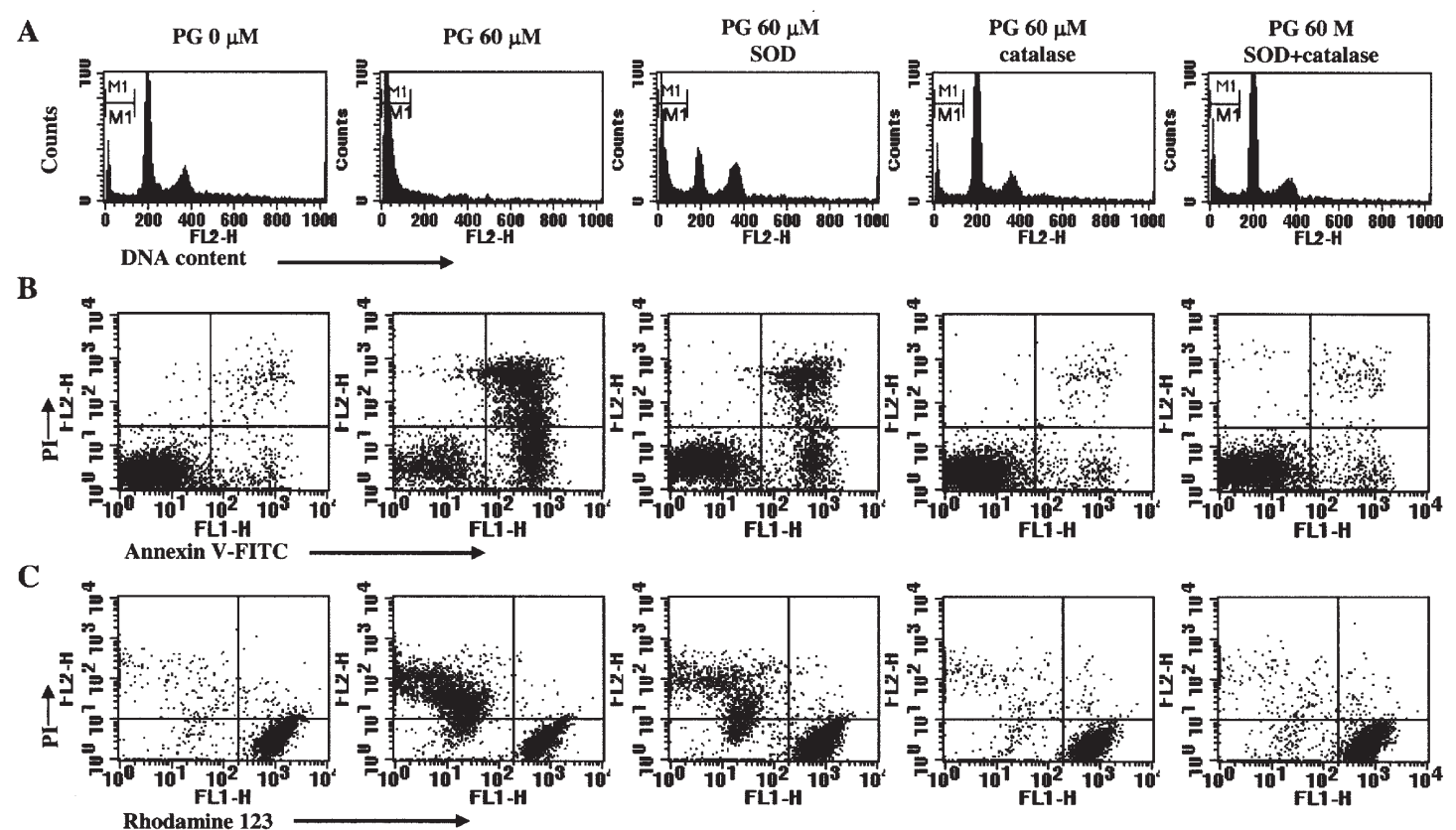

D

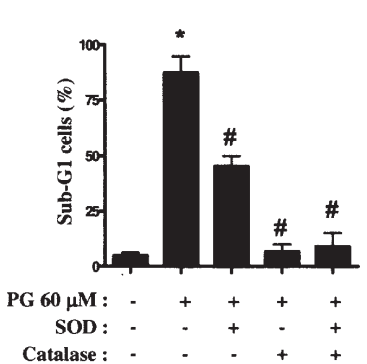

$\mathbf{E}$

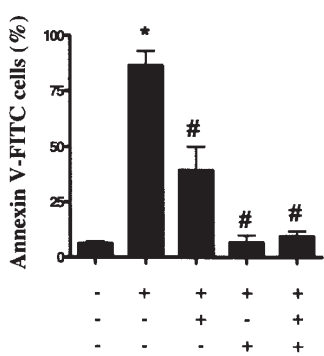

$\mathbf{F}$

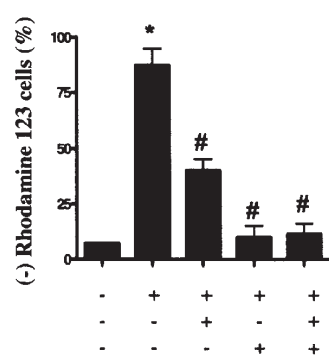

Figure 7. Effects of SOD and catalase on pyrogallol-induced apoptosis. Exponentially growing cells were treated with the indicated amounts of SOD, catalase and pyrogallol (PG) for $72 \mathrm{~h}$. (A) Sub-G1 cells, (B) annexin V-positive cells and (C) Rhodamine 123-negative cells were measured with flow cytometric analysis as described in Materials and methods. (D, E and F) Percentages of: sub-G1 population shown in A (D); annexin-positive cells shown in B (E) and Rhodamine 123-negative cells shown in $\mathrm{C}(\mathrm{F}) .{ }^{*} \mathrm{p}<0.05$ compared with the control group; ${ }^{\#} \mathrm{p}<0.05$ compared with the cells treated only with PG.

increased the levels of ROS in pyrogallol-treated HeLa cells and catalase also increased the intracellular ROS. In regard to the $\mathrm{O}_{2}{ }^{--}$levels in relation to SOD and catalase, SOD did not decrease the $\mathrm{O}_{2}^{-*}$ levels but catalase significantly decreased the $\mathrm{O}_{2}{ }^{-}$levels in pyrogallol-treated cells (Fig. 6B). When we assessed the levels of intracellular GSH, SOD and catalase significantly inhibited the depletion of GSH content in HeLa cells treated with pyrogallol (Fig. 6C). Catalase showed a stronger effect on recovery of GSH depletion than SOD. However, treatment with catalase did not recover the reduced GSH levels in pyrogallol-treated cells at the early time points (30-180 min) (data not shown). No synergistic or additive effects of SOD and catalase on the inhibition of GSH depletion were detected.

Next, we examined whether SOD and catalase could prevent pyrogallol-induced HeLa cell death. SOD and catalase significantly decreased apoptosis in HeLa cells treated with pyrogallol (Fig. 7). Catalase strongly decreased the sub-G1 cells and the annexin V-positive stained cells in pyrogallol-treated HeLa cells by approximately $80 \%$ (Fig. 7A and D, and Fig. 7B and E, respectively). In addition, catalase showed a stronger effect on reducing the loss of mitochondrial transmembrane potential $\left(\Delta \Psi_{\mathrm{m}}\right)$ in pyrogallol-treated HeLa cells than did SOD (Fig. 7C and F). There were no synergistic or additive effects of SOD and catalase on the reduction of apoptosis. In regard to CMF-negative and PI-positive cells, SOD reduced the proportion of CMF-negative and PIpositive cells induced by pyrogallol, and catalase was stronger in reducing the proportion than was SOD (Fig. 8A and $\mathrm{B}$ ). Interestingly, the negative CMF-fluorescent cells in pyrogallol and catalase-treated cells showed a small number of PI-positive cells (Fig. 8A and C), indicating that catalase strongly maintained the integrity of the cell membrane in pyrogallol-treated cells.

\section{Discussion}

In this study, we focused on the involvement of ROS such as $\mathrm{H}_{2} \mathrm{O}_{2}$ and $\mathrm{O}_{2}^{--}$, and GSH in pyrogallol-induced HeLa cell death. Our data showed that the intracellular ROS levels (DCF fluorescence intensity) were increased in $20 \mu \mathrm{M}$ pyrogallol-treated cells. However, the general ROS levels were decreased in HeLa cells treated with higher doses of pyrogallol (40-200 $\mu \mathrm{M})$. It is possible that the leakage of DCF dye occurred due to cell death after treatment with the higher doses of pyrogallol. Pyrogallol is often used to investigate 
A

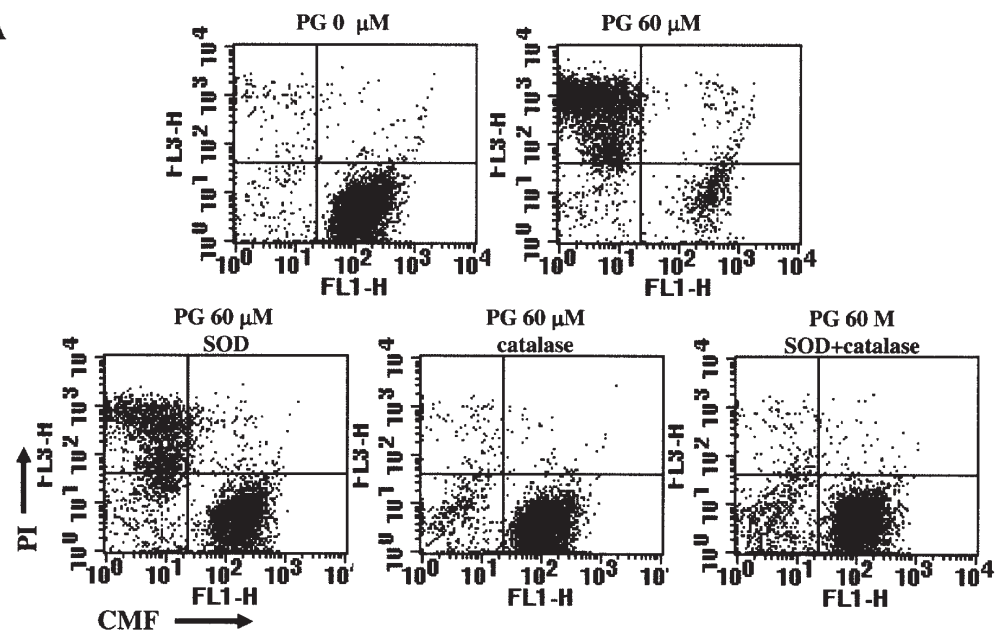

B

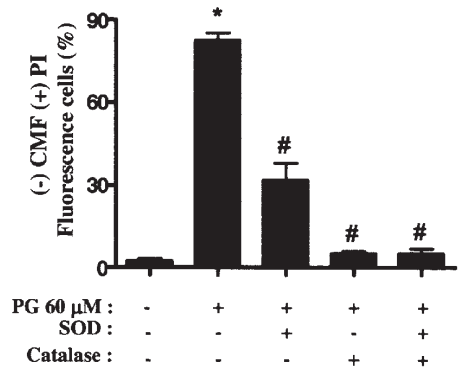

C

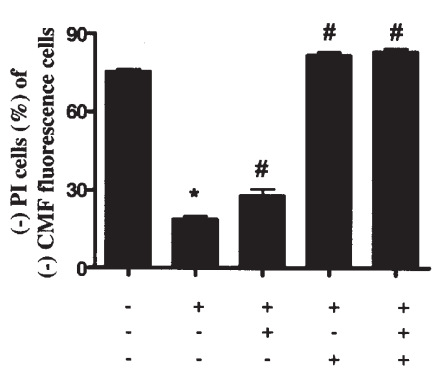

Figure 8. Effects of SOD and catalase on CMF and cell viability in pyrogallol-treated HeLa cells. Exponentially growing cells were treated with the indicated amounts of SOD and catalase in addition to pyrogallol (PG) for $72 \mathrm{~h}$. (A) CMF-fluorescent and PI-positive staining cells were measured with a FACStar flow cytometer. (B) Percentages of CMF-negative and PI-positive staining cells shown in A. (C) Percentages of PI-negative cells in CMF-negative-fluorescent cells shown in A. ${ }^{*} \mathrm{p}<0.05$ compared with the control group; ${ }^{*} \mathrm{p}<0.05$ compared with the cells treated only with PG.

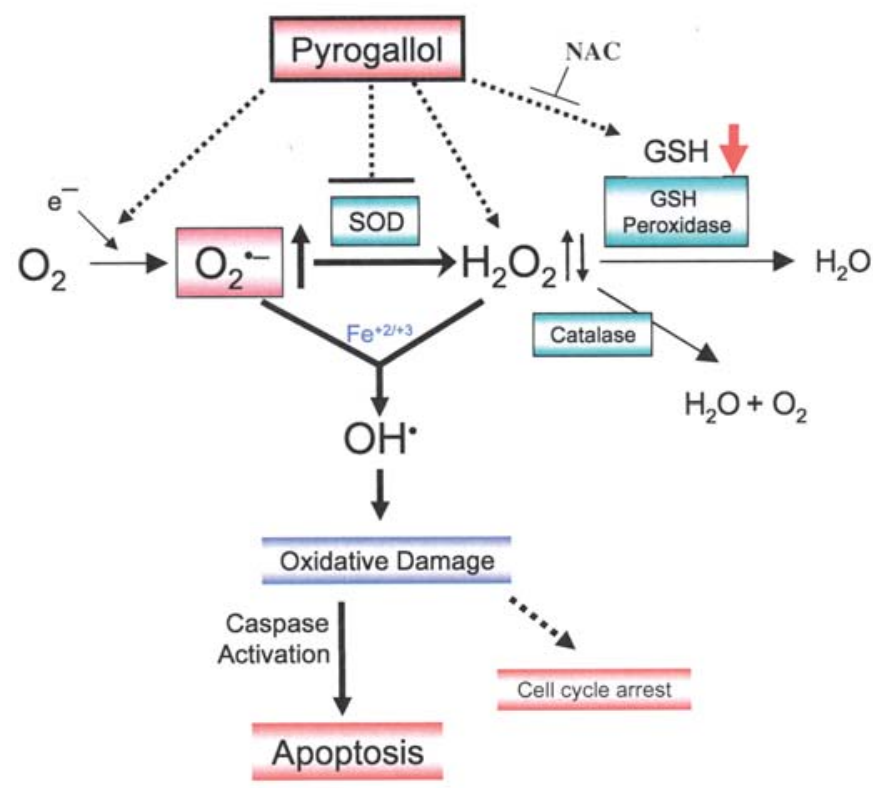

Figure 9. Scheme for pyrogallol-induced HeLa cells death through ROS and GSH, summarising the results of the study.

the role of $\mathrm{O}_{2}^{--}$in biological systems. As we expected, the intracellular $\mathrm{O}_{2}^{*}$ levels were significantly increased in a dosedependent manner. One interpretation of these increases is that pyrogallol strongly inhibited SOD activity (Fig. 1E), resulting in an accumulation in $\mathrm{O}_{2}{ }^{-}$level due to a slow conversion from $\mathrm{O}_{2}{ }^{-}$to $\mathrm{H}_{2} \mathrm{O}_{2}$.

It has been suggested that the apoptotic effects of pyrogallol are correlated with the changes of intracellular $\mathrm{O}_{2}{ }^{-}$ level in pheochromocytoma PC12 cells (11), human neuroblastoma SH-SY5Y cells (23) and juxtaglomerular As4.1 cells (24). Therefore, we attempted to determine whether ROS scavengers prevent pyrogallol-induced cell death through the reduction of intracellular $\mathrm{O}_{2}{ }^{-}$levels. In contrast to our expectations, all the scavengers used in this experiment did not significantly reduce the level of $\mathrm{O}_{2}{ }^{-}$in HeLa cells treated with $60 \mu \mathrm{M}$ pyrogallol. Tiron significantly increased the level of $\mathrm{O}_{2}{ }^{-}$. The weak effects of these scavengers, especially Tempol and Tiron as $\mathrm{O}_{2}{ }^{-}$scavengers, may be due to the lower doses used or/and the long incubation periods, since Yamada et al showed that the effects of Tempol and Tiron on reduction in $\mathrm{O}_{2}{ }^{-}$levels occurred at $3 \mathrm{~h}$ and at more than $1 \mathrm{mM}$ concentration of those in pyrogallol-treated PC12 cells (11). In addition, these scavengers with the exception of NAC could not reduce apoptosis in pyrogallol-treated cells. In particular, Tiron increased apoptosis levels with the increase of $\mathrm{O}_{2}^{-\cdots}$ production. As Tiron can also generate superoxide as a catechol under different conditions, this may enhance the toxicity of pyrogallol in these experimental conditions. Conversely, NAC significantly decreased apoptosis levels without the reduction of the intracellular $\mathrm{O}_{2}{ }^{-}$levels in 
pyrogallol-treated cells. This inhibition was accompanied by the down-regulation of the proapoptotic protein, Bax, and the inactivation of caspase-3 (data not shown). The treatment with exogenous SOD and catalase significantly inhibited apoptosis in pyrogallol-treated HeLa cells. However, exogenous SOD treatment did not reduce the intracellular $\mathrm{O}_{2}{ }^{--}$levels. It is possible that exogenous SOD did not enter cells to reduce the $\mathrm{O}_{2}^{--}$levels or the variety of SOD isoforms exists in cells. Catalase also down-regulated $\mathrm{O}_{2}{ }^{-}$levels in pyrogallol-treated cells. These results suggest that the changes of intracellular $\mathrm{O}_{2}{ }^{-*}$ level are at least partially correlated to apoptosis in pyrogallol-treated HeLa cells. In addition, the exact mechanisms of cell death through intracellular ROS in pyrogallol-treated HeLa cells still need to be defined further.

With regard to intracellular GSH, a main non-protein antioxidant in the cell, it is able to clear away the superoxide anion free radical and provide electrons for enzymes such as glutathione peroxidase, which reduce $\mathrm{H}_{2} \mathrm{O}_{2}$ to $\mathrm{H}_{2} \mathrm{O}$. It has been reported that intracellular GSH content has a decisive effect on anticancer drug-induced apoptosis, indicating that apoptotic effects are inversely comparative to GSH content $(25,26)$. We have also demonstrated that pyrogallol induces apoptosis in As4.1 juxtaglomerular cells through the depletion of intracellular GSH content (27). Likewise, our current result clearly indicated the depletion of intracellular GSH content by pyrogallol in HeLa cells. These results support that the change of intracellular GSH levels is tightly correlated with pyrogallol-induced cell death. In fact, NAC showing significantly the recovery of GSH depletion was found to decrease PI-positive cells in pyrogallol-treated HeLa cells. In addition, we observed that the level of GSH content in pyrogallol-treated HeLa cells was decreased about $50 \%$ at the early time point of $30 \mathrm{~min}$. However, at this time, the $\mathrm{O}_{2}{ }^{-}$ level in these cells was not strongly increased. These results suggested that pyrogallol plays a role as a GSH depletor itself, as well as an $\mathrm{O}_{2}{ }^{--}$generator. Treatment with catalase showed a stronger effect on the recovery of GSH depletion induced by pyrogallol than SOD. This result is consistent with the notion that the redox system can maintain normal intracellular GSH levels by regulating catalase and peroxidase activity rather than SOD. Such a proportion of GSH content regulated by SOD and catalase in pyrogallol-treated HeLa cells could also be applicable to apoptosis levels such as annexin $\mathrm{V}$-positive staining and the loss of mitochondrial transmembrane potential $\left(\Delta \Psi_{\mathrm{m}}\right)$. In fact, catalase had a strong anti-apoptotic effect compared with SOD. Treatment with catalase also significantly maintained the integrity of the plasma membrane in CMF-negative cells. We observed no synergistic or additive effects of SOD and catalase on ROS levels, GSH content and apoptosis parameters. It is possible that catalase works downstream of SOD and the level of intracellular GSH regulated by catalase is a critical factor in triggering apoptosis.

In summary, we demonstrated that pyrogallol potently increased intracellular ROS, especially $\mathrm{O}_{2}{ }^{--}$and decreased GSH content in HeLa cells, and NAC, SOD and catalase significantly rescued cells from pyrogallol-induced apoptosis accompanied by the recovery of GSH depletion (Fig. 9).

\section{Acknowledgements}

This research was supported by the Korea Research Foundation Grant funded by the Korean Government (MOEHRD) and the Korean Science and Engineering foundation (R01-2006-000-10544-0).

\section{References}

1. Gonzalez C, Sanz-Alfayate G, Agapito MT, Gomez-Nino A, Rocher A and Obeso A: Significance of ROS in oxygen sensing in cell systems with sensitivity to physiological hypoxia. Respir Physiol Neurobiol 132: 17-41, 2002.

2. Baran CP, Zeigler MM, Tridandapani S and Marsh CB: The role of ROS and RNS in regulating life and death of blood monocytes. Curr Pharm Des 10: 855-866, 2004.

3. Bubici C, Papa S, Pham CG, Zazzeroni F and Franzoso G: The NF-kappaB-mediated control of ROS and JNK signaling. Histol Histopathol 21: 69-80, 2006.

4. Zorov DB, Juhaszova $M$ and Sollott SJ: Mitochondrial ROSinduced ROS release: An update and review. Biochim Biophys Acta 1757: 509-517, 2006.

5. Wilcox CS: Reactive oxygen species: roles in blood pressure and kidney function. Curr Hypertens Rep 4: 160-166, 2002.

6. Chen TJ, Jeng JY, Lin CW, Wu CY and Chen YC: Quercetin inhibition of ROS-dependent and -independent apoptosis in rat glioma C6 cells. Toxicology 223: 113-126, 2006.

7. Dasmahapatra G, Rahmani M, Dent P and Grant S: The tyrphostin adaphostin interacts synergistically with proteasome inhibitors to induce apoptosis in human leukemia cells through a reactive oxygen species (ROS)-dependent mechanism. Blood 107: 232-240, 2006

8. Wallach-Dayan SB, Izbicki G, Cohen PY, Gerstl-Golan R, Fine A and Breuer R: Bleomycin initiates apoptosis of lung epithelial cells by ROS but not by Fas/FasL pathway. Am J Physiol Lung Cell Mol Physiol 290: L790-L796, 2006.

9. Simon HU, Haj-Yehia A and Levi-Schaffer F: Role of reactive oxygen species (ROS) in apoptosis induction. Apoptosis 5: 415-418, 2000

10. Saeki K, Hayakawa S, Isemura M and Miyase T: Importance of a pyrogallol-type structure in catechin compounds for apoptosisinducing activity. Phytochemistry 53: 391-394, 2000

11. Yamada J, Yoshimura S, Yamakawa H, et al: Cell permeable ROS scavengers, Tiron and Tempol, rescue PC12 cell death caused by pyrogallol or hypoxia/reoxygenation. Neurosci Res 45: 1-8, 2003

12. Yang X, Doser TA, Fang CX, et al: Metallothionein prolongs survival and antagonizes senescence-associated cardiomyocyte diastolic dysfunction: role of oxidative stress. FASEB J 20: 1024-1026, 2006.

13. Moreno-Manzano V, Ishikawa Y, Lucio-Cazana J and Kitamura M: Selective involvement of superoxide anion, but not downstream compounds hydrogen peroxide and peroxynitrite, in tumor necrosis factor-alpha-induced apoptosis of rat mesangial cells. J Biol Chem 275: 12684-12691, 2000.

14. Sawada M, Nakashima S, Kiyono $\mathrm{T}$, et al: p53 regulates ceramide formation by neutral sphingomyelinase through reactive oxygen species in human glioma cells. Oncogene 20: 1368-1378, 2001

15. Kim SW, Han YW, Lee ST, et al: A superoxide anion generator, pyrogallol, inhibits the growth of HeLa cells via cell cycle arrest and apoptosis. Mol Carcinog 47: 114-125, 2007.

16. Park WH, Jung CW, Park JO, et al: Trichostatin inhibits the growth of ACHN renal cell carcinoma cells via cell cycle arrest in association with p27, or apoptosis. Int J Oncol 22: 1129-1134, 2003.

17. Park WH, Seol JG, Kim ES, et al: Arsenic trioxide-mediated growth inhibition in MC/CAR myeloma cells via cell cycle arrest in association with induction of cyclin-dependent kinase inhibitor, p21, and apoptosis. Cancer Res 60: 3065-3071, 2000.

18. Han YH, Kim SH, Kim SZ and Park WH: Intracellular GSH levels rather than ROS levels are tightly related to AMAinduced HeLa cell death. Chem Biol Interact 171: 67-78, 2008.

19. Poot M, Teubert H, Rabinovitch PS and Kavanagh TJ: De novo synthesis of glutathione is required for both entry into and progression through the cell cycle. J Cell Physiol 163: 555-560, 1995. 
20. Schnelldorfer T, Gansauge S, Gansauge F, Schlosser S, Beger HG and Nussler AK: Glutathione depletion causes cell growth inhibition and enhanced apoptosis in pancreatic cancer cells. Cancer 89: 1440-1447, 2000.

21. Tikhaze AK, Lankin VZ, Zharova EA and Kolycheva SV: Trimetazidine as indirect antioxidant. Bull Exp Biol Med 130: 951-953, 2000.

22. Stanley WC and Marzilli M: Metabolic therapy in the treatment of ischaemic heart disease: the pharmacology of trimetazidine. Fundam Clin Pharmacol 17: 133-145, 2003.

23. Poulose SM, Harris ED and Patil BS: Citrus limonoids induce apoptosis in human neuroblastoma cells and have radical scavenging activity. J Nutr 135: 870-877, 2005.
24. Park WH, Han YH, Kim SH and Kim SZ: Pyrogallol, ROS generator inhibits As4.1 juxtaglomerular cells via cell cycle arrest of G2 phase and apoptosis. Toxicology 235: 130-139, 2007.

25. Estrela JM, Ortega A and Obrador E: Glutathione in cancer biology and therapy. Crit Rev Clin Lab Sci 43: 143-181, 2006.

26. Higuchi Y: Glutathione depletion-induced chromosomal DNA fragmentation associated with apoptosis and necrosis. J Cell Mol Med 8: 455-464, 2004

27. Park WH, Han YW, Kim SH and Kim SZ: A superoxide anion generator, pyrogallol induces apoptosis in As4.1 cells through the depletion of intracellular GSH content. Mutat Res 619: 81-92, 2007. 